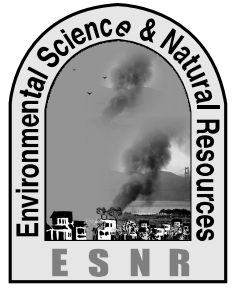

\title{
Effect of Seed Category as Affected by Bipolaris sorokiniana on the Germination of Wheat Seeds
}

\author{
A. Sultana and A. Q. M. B. Rashid
}

Seed Pathology Center, Bangladesh Agricultural University, Mymensingh

\begin{abstract}
An experiment was conducted under in-vitro condition to determine the effect of wheat seed categories such as healthy looking, blackpointed and shriveled as affected by Bipolaris sorokiniana on the germination of wheat seeds. The work was done in the laboratory of Seed Pathology Center, Bangladesh Agricultural University, Mymensingh during 2010-11. The highest prevalence $(65 \%)$ of B. sorokiniana was recorded in shriveled seeds, (42\%) was recorded in blackpointed seeds, and (30\%) was associated with healthy looking seeds. The pathogen was responsible for the highest germination failure (87\%) found in the category of shriveled seeds and then (35\%) was found in blackpointed seeds while the healthy looking seeds showed (24\%) germination failure. The result suggests that, the shriveled and blackpointed seed samples must be rejected, and after proper seed health test in an only the healthy looking seeds may be recommended for sowing through proper seed treatment.
\end{abstract}

Key words: B. sorokiniana, Germination, Seed category, Wheat seed

\section{Introduction}

Bipolaris sorokiniana (Sacc. in sorok.), Drechslera sorokiniana (Sacc.) and Cochliobolus sativus (Ito and Kurib) has been reported to be the most important and serious concern to both wheat growers and researchers in the world (CIMMYT, 1991). It is worldwidely very aggressive pathogen of wheat in the warmer areas including Bangladesh (Dubin and Ginkel, 1991). The importance and distribution of seedborne $B$. sorokiniana in wheat has been reported in Bangladesh (Rashid et al., 1992). This pathogen is ubiquitous in nature but highly seed borne and seed transmitted in wheat (Rashid and Neergaard, 1996; Fakir et. al., 1997). The seed borne infection by this pathogen results the seed to be blackpointed and shriveled, lowering the market value as well as planting value of the seeds which ultimately affects the cultivation of wheat in the country (Rashid et. al., 2004). With the increased and intensified cultivation of crops in Bangladesh this pathogen has become a serious concern to the producers, dealers, growers and researchers (Rashid and Fakir, 2003). Therefore, the present work was undertaken to explore the effect of the pathogen on the germination of various categories of wheat seeds.

\section{Materials and Methods}

Seed samples of widely cultivated wheat cultivar 'Shatabdi' were collected from Bangladesh Agricultural Development Corporation (BADC) and were tested in the Seed Pathology Centre, Bangladesh Agricultural University during the period from 2010-11.The collected seed samples were categorized as healthy looking, blackpointed and shriveled through dry inspection method (Fig. 1).

i. Apparently healthy looking seed The seeds were morphologically normal in size and shape with usual smooth surface and natural bright color.

ii. Blackpointed seed The blackpointed seeds were with the characteristic black discoloration usually at around the embryonic region, usually showed rough surface and fade color. In some cases, the black discoloration extends beyond the germ end to ventral side or the sulcus, the most important harboring site of the pathogen. In severe cases, the whole grain was discolored and shriveled. The severity of blackpoint in seed was increased with the increase of infection. Higher leaf infection ultimately resulted more blackpointed seeds.

iii. Shriveled seed the shriveled seeds were usually small, deformed and of variable shapes and sizes with rough and black wrinkled surface.

Seed health test was done by standard blotter method (ISTA, 1976) where the presence of pathogen was confirmed by observing under compound steriobinocular microscope.

\section{Results and Discussion}

Data were recorded on blottered seeds (Fig. 2) since the third day of incubation. With the progress of incubation period the growth and development of pathogen was also gradually increased. The prevalence of the pathogen in various categories of wheat seeds as affected by the pathogen has been shown in (Fig. 3). 


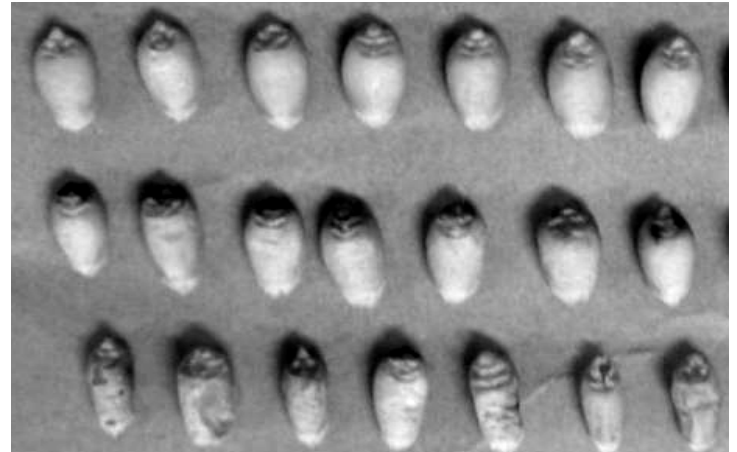

Fig. 1. Categories of the wheat seeds. Apparently healthy looking (top), blackpointed (middle) and shriveled seeds (bottom).

The prevalence of the pathogen was the highest $(65 \%)$ in shriveled seeds, moserate was in blackpointed seeds (42\%) and the lowest was in the healthy looking seeds (30\%) (Fig.3). With the progress of incubation period the most aggressive growth of the pathogen along with sporulation arrested and deteriorated the whole germinating seeds. In such cases, the plumule or sprouting young seedling and the radicle were completely destroyed and killed with no or poorly developed root system. The prevalence and transmission of the pathogen

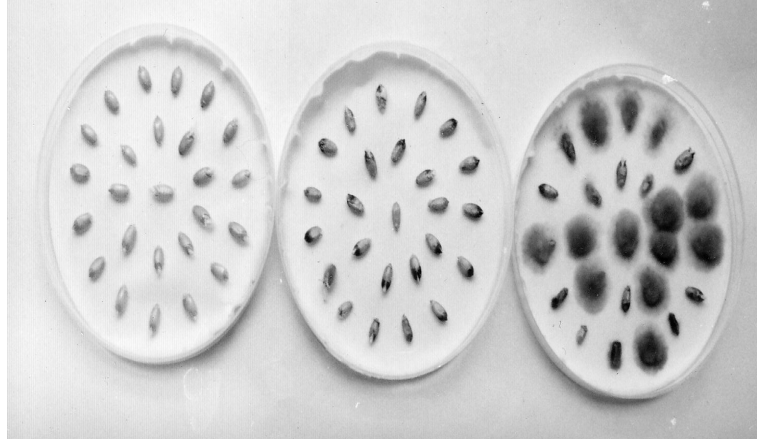

Fig. 2. Prevalence of $B$. sorokiniana in healthy looking (left), blackpointed (middle) and shriveled seeds (right) on the moist blotter.

associated with the seeds to the sprouts resulted various impairments. The pathogenic growth and sporulation affected the germinating plumule where the infected sprouts resulted the failure of germination (Anonymous, 1989; Rashid and Neergaard 1996). From the results, it may be said that though the maximum germinating seeds were affected with vigorous mycelial growth and sporulation, other seeds were also observed equally victimized as regard to germination in shriveled category of seeds.

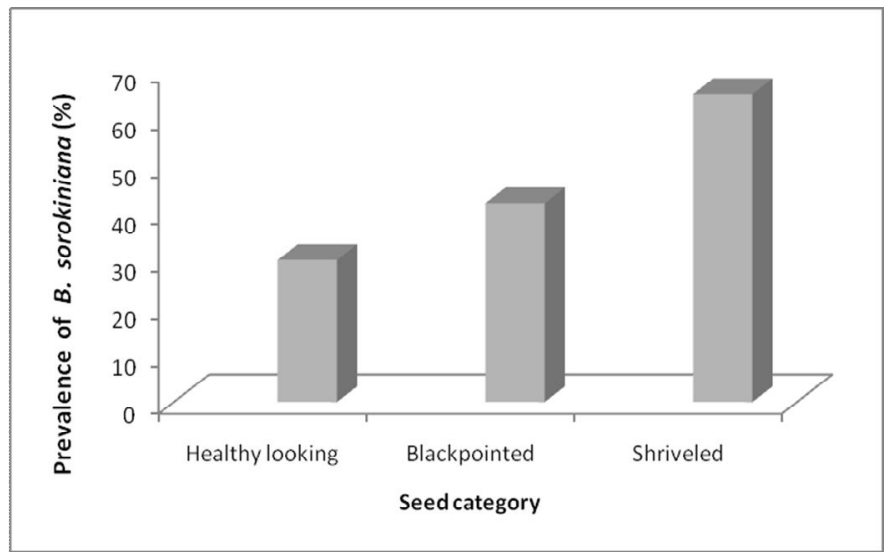

Fig. 3. Prevalence of $B$. sorokiniana in different categories of wheat seeds in blotter

It is revealed from the (Fig. 4) that the highest sprouting deterioration in terms of seed rot, coleoptiles and coleorhizae infection, post emergence sprout infection etc. were recorded as high as $87 \%$ in case of the shriveled seeds. The blackpointed seeds yielded $35 \%$ deterioration followed by the apparently healthy looking seeds $24 \%$. After sowing the same conditions that caused the seed to germinate the same condition are equally applicable for the dormant pathogen for growing. During germination of seeds, along with fungal growth, a competition in between the sprouting seeds and growth of the pathogen occurs. Kumar et al. (2002) observed that $B$. sorokiniana initiated epidemics by infecting the primary leaf via the coleoptile during seedling emergence where the heavily infected seedlings may fail to emerge. According to Mehta (1997) spot blotch of wheat caused by $B$. sorokiniana adversely 
affect the root system development or kill the seedling within a few days and capable of causing up to $100 \%$ yield losses corroborating with the findings of Hossain and Azad (1994). The pathogen $B$. sorokiniana has been found to reduce $88.7 \%$ grain/ear and produced $87.5 \%$ discolored and blackpointed grains (Hossain et al., 1998). Blackpoint of wheat caused by $B$. sorokiniana is a disease of grain resulting discoloration at the embryal stage.

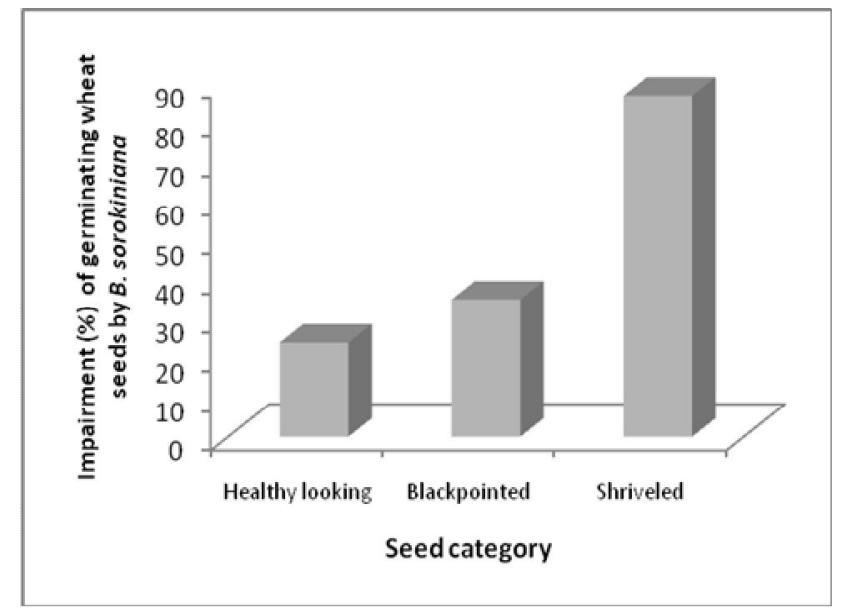

Fig. 4. Effect of B. sorokiniana during germination in different categories of wheat seeds in blotter.

\section{Conclusions}

The blackpointed and shriveled seeds lower the market value and the planting value of wheat seeds which ultimately affecting cultivation of wheat. With the increased and intensified cultivation of the crop, the pathogen may become a serious concern to the producers, dealers, growers and researchers. Under such conditions the blackpointed and shriveled category of seeds may be screened out by applying proper seed health approach before sowing. Suitable seed treatment measures may also be adopted for the healthy looking category of seeds, where germination percentage is nearly allowable for desired plant population against the pathogen.

\section{References}

Anonymous, 1989. Research findings, Progress Report, January 1988, Seed pathology Laboratory, Bangladesh Agricultural University, Mymensingh.9-11.

Rashid, A. Q. M. B., Meah, M. and Fakir, G.A. 1992. Importance and distribution of seed borne Bipolaris sorokiniana in wheat in Bangladesh. Bangladesh Journal of Plant Pathology, 8: (9)11.
Rashid, A. Q. M. B. and Neergaard, E. 1996. Histopathological behavior of seedborne Bipolaris sorokiniana in wheat seedling. Bangladesh Journal of Plant Pathology, 12:(5)-8.

Rashid, A. Q. M. B. and Fakir, G. A. 2003. Occurrence and severity of Bipolaris leaf blight of wheat in Bangladesh in 1998 and 1999. Bangladesh Journal of Seed Science and Technology, 7(12) : 29-34.

Rashid, A. Q. M. B.; Dhar, R.C. and Khalequzzaman, K. M. 2004. Association of Bipolaris sorokiniana in wheat seed and its effect on subsequent plant infection at different growth stages. Journal of Agriculture and Rural Development, 2(1): 67-72.

Rashid, A. Q. M. B. and Fakir, G. A. 2003. Morphology and architecture of seed infected with Bipolaris sorokiniana and its impact on planting value of wheat. Bangladesh Journal of Progressive Science and Technology, 1 (1): 7-9.

CIMMYT. 1991. Wheat for the non traditional warm areas. Mexico, D. F. ed. Saunders, D. A.

Dubin, H. J. and Ginkel, M. V. 1991. The status of wheat diseases and disease research in warmer areas. Wheat for the Nontraditional Warmer Areas. (Ed. Saunders, D. A.) CIMMYT, Mexico, D. F, P. 125-145.

Hossain, I. and Azad, A.K. 1994. B. sorokiniana its reaction and effect on yield of wheat. Bangladesh Journal of Progressive Agriculture, 5(2) : 63-69. 
Hossain, I.; Rashid, A. Q. M. B., Fakir, G.A. and Meah, M.B. 1998. Leaf blight of wheat: its status and impact on grain formation. First National Workshop on Seed Pathology, progress and prospect of seed pathological research in Bangladesh. Department of Plant Pathology, Bangladesh Agricultural University, Mymensingh, 9-10pp.

Fakir, G. A., Khan, A. L., Neergaard, P. and Mathur, S. B. 1997. Transmission of Drechslera sp. Through wheat seed in Bangladesh. Bangladesh Journal of Progressive Agriculture, 1: 113-118.
ISTA. 1976. International Roles of Seed Testing Association. Proceeding of International Seed Testing Association. 180p.

Kumar, J. and K. Heinzkogel 2002. Bipolaris sorokiniana, a cereal pathogen of global concern: cytological and molecular approaches towards better control. Molecular Plant Pathology, 3(4): 185-195.

Mehta, Y. R. 1997. Constraints towards the integrated management of spot blotch of wheat. Helminthosporium blights of wheat: spot blotch and Tan spot. Proceedings of an international workshop held at CIMMYT. El Batan, Mexico, 18$27 \mathrm{pp}$. 